\title{
Current Status of Nerve Transfers: "Supercharge End-to-Side Transfer in Severe Cubital Syndrome"
}

\author{
Salmeron Martinez EJ ${ }^{1 *}$, Castellanos Moreno $\mathrm{A}^{2}$ and Ubeda Garcia $\mathrm{FM}^{3}$ \\ ${ }^{1}$ Associate clinical professor of traumatology and orthopedic surgery, Murcia University, Spain \\ ${ }^{2}$ Graduated in Medicine and Surgery, UMU University, Spain \\ ${ }^{3}$ Associate Professor of Anatomy, UCAM University, Spain
}

*Corresponding author: Salmeron Martinez EJ, MD PhD, Associate clinical professor of traumatology and orthopedic surgery, Murcia University, UMU, Spain; Staff Orthopaedic Surgeon, Morales Meseguer University Hospital, Spain, Email: ejsalmeron@yahoo.es

\section{Research Article \\ Volume 4 Issue 2}

Received Date: September 30, 2020

Published Date: October 14, 2020

DOI: $10.23880 /$ jobd -16000200

\section{Abstract}

Supercharge end-to-side (SETS) technique has been increasingly implemented in the treatment of nerve pathologies. It was known for its use in ulnar injury, and although it seemed that its usefulness was more directed to injuries due to ulnar nerve section, with this work and based on all the literature available to date, the aim is to assess the possibilities of implementation based on the results of the articles published in compression-type injuries, especially those classified as severe that have little treatment available to improve their evolutionary course, and where their use to date was doubtful.

A compilation is made of all the evidence to date of cubital tunnel syndrome, focused on treatments, and on the emergence of the SETS technique as a therapeutic option. The purpose of the study was to collect and review the indications, results, and complications of end-to-side axonal super feeding transfer of the interosseous nerve anterior to the ulnar nerve.

Twenty-one articles that met the inclusion and exclusion criteria were finally reviewed, most of them retrospective (level of evidence IV) and some review or case series (level of evidence II/ III). The data has been pooled and analyzed focusing on the primary outcomes: intrinsic muscle recovery and complications.

SETS is a successful procedure with low morbidity, which can restore the function of the intrinsic musculature in patients with severe proximal ulnar nerve compression injuries thanks to the anterior interosseous nerve (median branch) that serves as a donor. Although the technique has already begun to be introduced in the sketch of the treatment of the lesion, to implement it with assured success, prospective studies should be carried out that corroborate it with greater certainty than the articles published on the subject to date. Even so, it has been possible to verify as previous indications for performing supercharge: a normal donor nerve electromyogram (it will be performed in a pronator square), a preoperative electromyogram of the injured nerve that must have a reduced amplitude of compound muscle action potential (demonstrating axonal loss) and an electromyogram to know if the denervated motor endplates remain receptive to reinnervation (check they have spontaneous activity and this is shown by fibrillation potentials and / or acute positive waves).

Keywords: Supercharge End to Side; Anterior Interosseous Nerve to Cubital; Lesion in Continuity; Supercharged Ulnar Nerve; Severe Ulnar Compression; Ulnar Tunnel Syndrome; Ulnar/Cubital Nerve Transfer 


\section{Journal of Orthopedics \& Bone Disorders}

\section{Material and Methods}

\section{Search Strategy}

According to the objectives explained in the previous section, the search was started. Keywords were selected "supercharge end to side", "Anterior interosseous nerve to cubital", "Lesion in continuity", "supercharged ulnar nerve", "severe ulnar compression", "ulnar tunnel syndrome" y "ulnar/ cubital nerve transfer".

These words were used to proceed to the bibliographic search in: Pubmed, Science Direct, Dialnet y Cochrane. Several articles were found in each search, selecting those that fit our inclusion and exclusion criteria.

\section{Article Selection Criteria}

\section{The inclusive criteria}

- Those articles that spoke about the SETS technique of anterior to ulnar interosseus in the treatment of entrapment of the ulnar nerve.

- Those who spoke of the treatment of cubital tunnel syndrome in severe stages, evaluating which surgical procedure is better.

- Those that generally describe the supercharge end to side technique and its historical evolution.

- Those who describe the technique anatomically.

\section{Exclusión criteria}

- Experimental articles on animals.

- Those who spoke of SETS, but on nerves other than cubita.

- $\quad$ Old articles where the SETS technique did not exist (since the technique was not carried out until 2009 for the first time).

- Outdated ulnar entrapment treatment guidelines and had another expanded later study.

- From the studies found, titles and abstracts were reviewed applying these criteria and the full text of those studies considered potentially relevant was selected.

\section{Search Results and Selected Studies}

The details of the searches in each of the search engines and databases, and of the selected articles are specified in the search table (Table 1).

\begin{tabular}{|c|c|c|c|c|c|}
\hline Database & Keywords & Search & Articles & Filters & $\begin{array}{c}\text { Final } \\
\text { articles }\end{array}$ \\
\hline \multirow{7}{*}{ PUBMED } & Supercharge end to side & Supercharge end to side & 16 & - & 11 , finally 8 \\
\hline & Anterior interosseous nerve & $\begin{array}{l}\text { Anterior interosseous } \\
\text { nerve to }\end{array}$ & \multirow[t]{2}{*}{26} & \multirow[t]{2}{*}{-} & \multirow[t]{2}{*}{3} \\
\hline & to cubital & cubital & & & \\
\hline & Supercharged ulnar nerve & $\begin{array}{c}\text { Supercharged ulnar } \\
\text { nerve }\end{array}$ & 8 & - & 3 \\
\hline & Lesion in continuity ulnar & $\begin{array}{c}\text { Lesion in continuity } \\
\text { ulnar }\end{array}$ & 22 & - & 10 , finally 3 \\
\hline & \multirow{2}{*}{ Severe ulnar compression } & \multirow{2}{*}{$\begin{array}{l}\text { Severe ulnar } \\
\text { compression }\end{array}$} & \multirow{2}{*}{$173: 04: 00$} & *Review & \multirow{2}{*}{2} \\
\hline & & & & *Last 5 years & \\
\hline \multirow{8}{*}{ COCHRANE } & Supercharged end to side & $\begin{array}{l}\text { Supercharged end to } \\
\text { side }\end{array}$ & 0 & All text & 0 \\
\hline & Anterior interosseous nerve & $\begin{array}{c}\text { Anterior interosseous } \\
\text { nerve to }\end{array}$ & \multirow[t]{2}{*}{2 Trials } & \multirow[t]{2}{*}{ All text } & \multirow[t]{2}{*}{1} \\
\hline & to cubital & cubital & & & \\
\hline & \multirow{2}{*}{ Lesion in continuity ulnar } & \multirow{2}{*}{$\begin{array}{l}\text { Lesion in continuity } \\
\text { ulnar }\end{array}$} & 32 Reviews & \multirow{2}{*}{ All text } & \multirow{2}{*}{1} \\
\hline & & & 2 Trials & & \\
\hline & \multirow{3}{*}{ Ulnar tunnel syndrome } & \multirow{3}{*}{ Ulnar tunnel syndrome } & 15 Reviews: 3 & $\begin{array}{c}\text { All text } \\
* \text { Seleccionamos }\end{array}$ & \multirow{3}{*}{4} \\
\hline & & & 124 trials: 1 & $\begin{array}{l}\text { las revisiones } \\
\text { más recientes } \\
\text { (que nos sirvan } \\
\text { de guía) }\end{array}$ & \\
\hline & & & 1 Clinical Answer & & \\
\hline
\end{tabular}




\section{Journal of Orthopedics \& Bone Disorders}

\begin{tabular}{|c|c|c|c|c|c|}
\hline \multirow{3}{*}{$\begin{array}{l}\text { SCIENCE } \\
\text { DIRECT }\end{array}$} & \multirow{3}{*}{$\begin{array}{l}\text { Supercharged end to side } \\
\text { transfer }\end{array}$} & $\begin{array}{l}\text { Supercharged end-to- } \\
\text { side transfer }\end{array}$ & 86 & $2017-2020$ & 6 , finally 1 \\
\hline & & $\begin{array}{c}\text { Supercharged end to } \\
\text { side }\end{array}$ & \multirow[t]{2}{*}{18} & \multirow[t]{2}{*}{ - } & \multirow[t]{2}{*}{2} \\
\hline & & transfer ulnar nerve & & & \\
\hline \multirow{8}{*}{ DIALNET } & Transferencia nerviosa & & 2 Tesis & & \\
\hline & cubital & $\begin{array}{c}\text { Iransierencla nerviosa } \\
\text { cubital }\end{array}$ & 1 Artículo revista & - & 0 \\
\hline & \multirow[b]{2}{*}{ Lesión cubital } & \multirow{2}{*}{$\begin{array}{l}\text { Lesión cubital } \\
\text { tratamiento }\end{array}$} & 18 Tesis & \multirow[b]{2}{*}{-} & \multirow[b]{2}{*}{0} \\
\hline & & & $\begin{array}{l}11 \text { Artículos } \\
\text { revista }\end{array}$ & & \\
\hline & \multirow{2}{*}{ Atrapamiento cubital } & \multirow{2}{*}{ Atrapamiento cubital } & 10 Tesis & \multirow{2}{*}{-} & \multirow{2}{*}{0} \\
\hline & & & 1 Artículo revista & & \\
\hline & \multirow[b]{2}{*}{ Síndrome túnel cubital } & Síndrome túnel cubital & 5 Tesis & \multirow[b]{2}{*}{-} & \multirow[b]{2}{*}{2} \\
\hline & & tratamiento & 2 Artículos revista & & \\
\hline
\end{tabular}

Table 1: Search details.

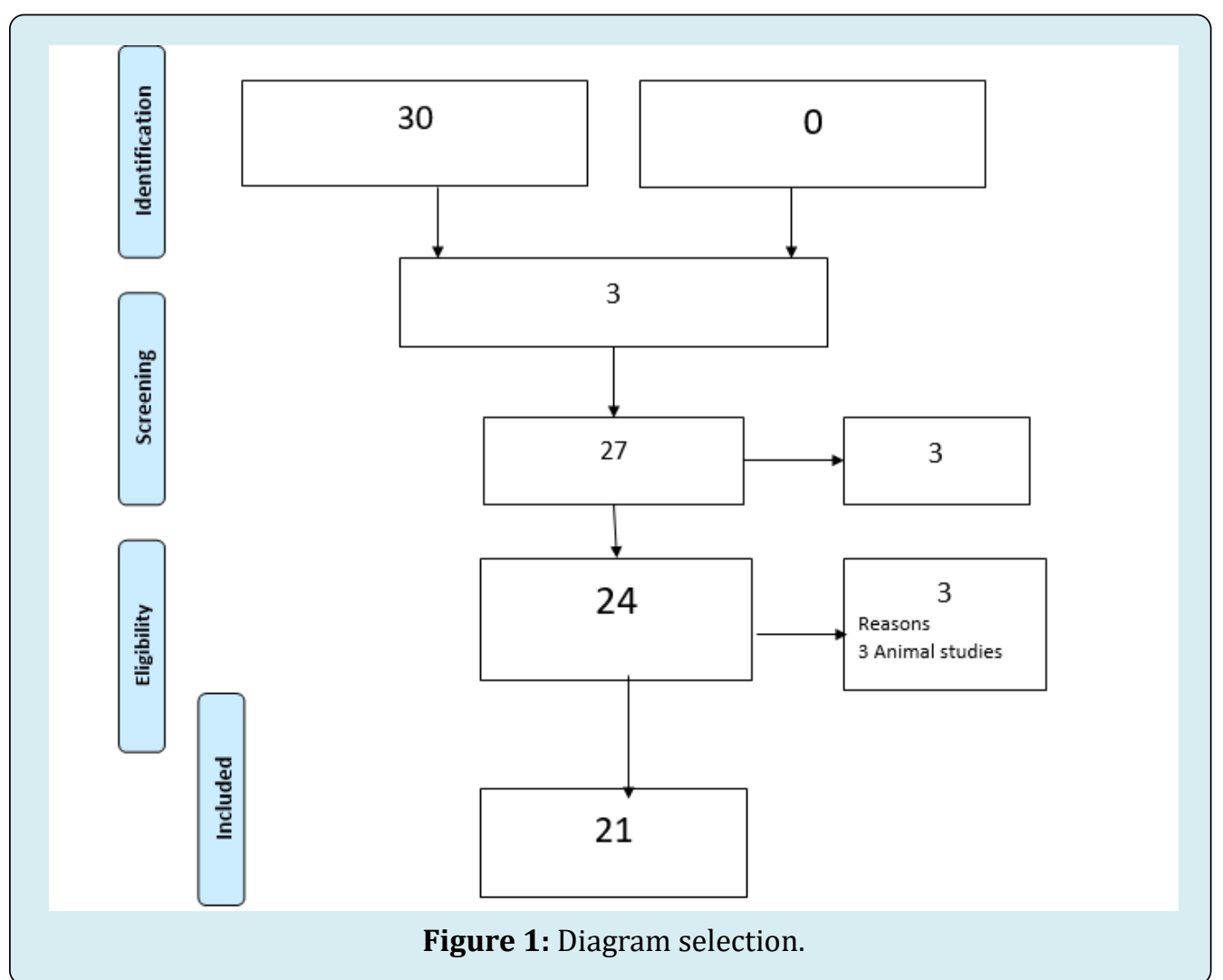

Based on these criteria, a total of 30 articles were initially selected, which, removing those duplicates among the different databases used, remained at 27. We divided these 27 articles into two themes:

$\checkmark$ Those who spoke only of the SETS technique (a total of 16).
Those that focused on the treatment of cubital tunnel syndrome (a total of 11). Of these eleven, we eliminated three as they are outdated or very old reviews $(2006,2007,2009)$ on the treatment of ulnar syndrome, which did not provide additional information to that already contained in the newer and updated ones. 


\section{Journal of Orthopedics \& Bone Disorders}

That made us keeps a total of 24 documents. After studying them in detail and reading them in full, we eliminated three of them for basing their results on animal models or not on humans (rats) and that were not perceived in the first screening of the articles. Thus, the truly interesting articles that focus on our objective were a total of 21. And this review revolves around them. Even so, many of the shortlisted served to provide nuances in our results, and will be referenced in our text.

You can also see more clearly the articles finally selected to review in the diagram made following the indications PRISMA 2009 (Figure 1).

\section{Results}

The search resulted in 30 potentially eligible studies, while only 21 met the inclusion and exclusion criteria (Figure 1).

In the following paragraphs the most important results in relation to our objective search have been grouped. Most of the studies found are retrospection of these, the following stand out: the opinions of experts with levels of evidence IV and V (based on levels of evidence and degrees of recommendation by the Canadian Task Force on Preventive Health Care), reviews and case series (level IV), letters to the editor (level IV), a paired retrospective cohort study (level III) and a systematic review (level II). As the only example of a prospective study we have found one that consists of a series of matched cases (level II). Therefore, after reviewing the available scientific evidence regarding the objectives set, we obtain the following results, which are set out below.

\section{Results on the use of the SETS Technique}

Efficiency and general indications of the NIA SETS technique for ulnar injury. The compilation of the indications and the use of the supercharge technique in ulnar nerve injury was carried out by means of a detailed review of the articles reviewed in this work. Within the total of 21 , we focused on thirteen of them, who were those who explicitly spoke of in which clinical situations of ulnar pathology it would be appropriate to use the technique and its proven efficacy in the different modalities of ulnar injury.

Knowing that the SETS transfer of the anterior interosseous nerve (NIA) to the ulnar motor branch was described in the late 1990s, and carried out in patients with ulnar compression syndrome in early 2009 , limited evidence studies were found as first results. (Level of evidence IV) that corresponded to expert opinions or retrospective reviews of the patients treated to date $[15,17,18,12]$.
The first chronological study was that of Barbour, et al. in 2012 [15], first to use and describe the technique, and they required broad clinical applicability for other types of lesions, such as those of the second or third degree of Sunderland (level of evidence IV), as the main indication for EESS.

In 2015, Davidge, et al. [12] reviewed their initial clinical experience with SETS in severe ulnar neuropathy, this study corresponding to the first retrospective on the subject (level of evidence IV). It consists of a study of 55 patients that demonstrated that $70 \%$ of patients achieved at least a grade 3 return of intrinsic function. Even so, these studies remain of low evidence to be able to have sufficient scientific weight.

Baltzer and his team [2] published in 2016 the first retrospective paired cohort study (level of evidence III) that focuses more than on indications, on demonstrating the benefit of using the technique compared to not using it and performing only one release. Although I obtained results such as the improvement of those patients in whom the technique is used, this study is diminished in its level of evidence by the small sample of patients they worked on (16 patients), also being retrospective.

Studies, now prospective, continue to be carried out in animals that have demonstrated the evaluation of the SETS technique quantifying the regenerating neuronal component, being much higher in rats in which SETS is performed compared to those that do not [19]. Parallel to these animal studies of series of cases in humans (level of evidence IV) such as that of 2018 have been continued, corroborating everything seen in laboratory studies in animals, analyzing clinical cases retrospectively [13].

From the technique as such and its efficacy and indication in ulnar injury, a unique systematic review was found that should correspond to a level II of evidence, but later it was demonstrated that it was not carried out correctly and therefore lost relevance [20].

The two articles with the most relevant results published after this, and more recent, were a prospective matched comparative series and an article by Mackinnon's own team (pioneers in talking about the supercharge technique) from 2020, which tries to redefine guidelines that are already clear. To the SETS technique in the treatment of ulnar injury.

The comparative series (the only prospective study found in Level II evidence) aims to compare combined ulnar nerve repair with EESS with conventional isolated ulnar repair techniques [14]. In the second article, as there is still controversy regarding the efficacy and appropriate clinical indications of supercharge in cubital tunnel syndrome, 


\section{Journal of Orthopedics \& Bone Disorders}

where the time of onset of axonal loss is less clear, the authors present guidelines for patient selection. , surgical technique, and postoperative rehabilitation based on their clinical experience with the technique in this patient population [21].

By compiling information in the literature reviewed in all the articles mentioned above, the indications that the technique has within cubital pathology have been synthesized. The indications for the SETS technique are generally very broad. It should be considered for mid-level injuries near the elbow or in injuries of the upper ulnar nerve with a Martin-Gruber anastomosis. This procedure is recommended for patients with second and third degree injuries with fibrillations and potentials of motor units or nascent units present in EMG (Figure 2) [15].
Additional indications include very proximal cell body injuries or cervical root injuries that are not amenable to surgical repair, and distal peripheral motor neuropathies (i.e., Charcot-Marie-Tooth). The technique is not indicated for patients with first-degree conduction block in the cubital tunnel, with normal motor units and without fibrillations in the EMG, even if they have intrinsic muscular involvement. But yes in severe ulnar syndrome with pathological EMG [15].

As these indications do not obey SETS, ETE can be done if nerve transfer is indicated in general (Figure 3) ETE transfers are appropriate in fourth and fifth degree proximal lesions when recovery through the native nerve is not expected [16].

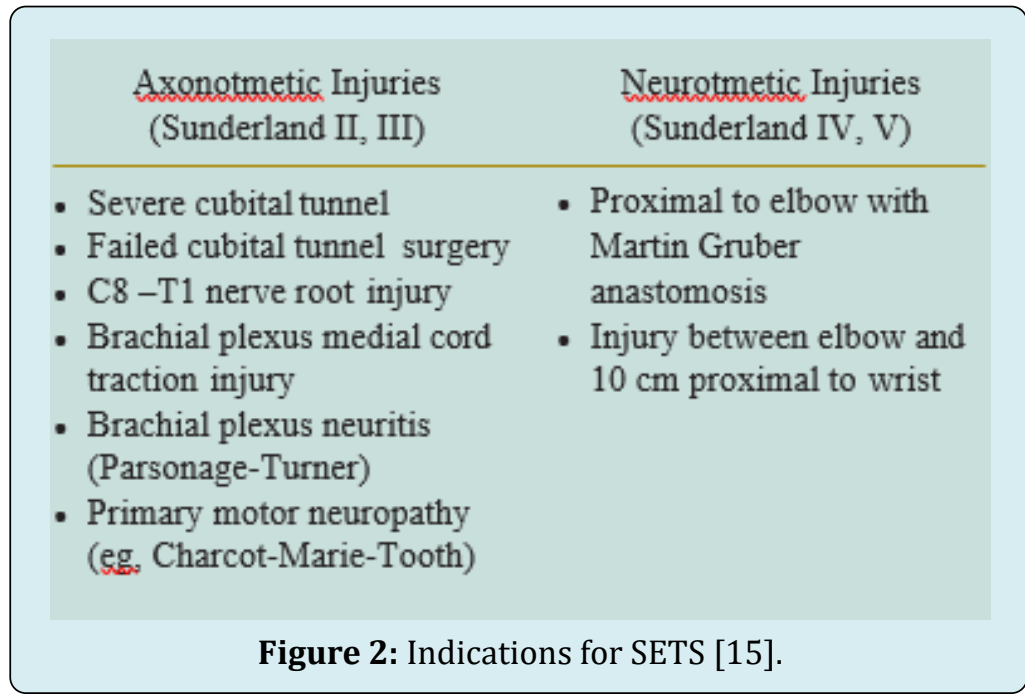

\begin{tabular}{|lllll|}
\hline \multicolumn{2}{|l}{ Indications for supercharged end to side nerve transfer } & & \\
& Degree & FIBS & MUPS & Transfer Type \\
\hline $\begin{array}{l}\text { Acute injury } \\
\text { High ulnar }\end{array}$ & IIIIII & 1 & Collateral sprouting, & SETS \\
& VIIN & 1 & - & nascent \\
& VI/V (Martin-Gruber) & 1 & Normal & STE \\
Mid ulnar & II/III & 1 & Collateral sprouting, & SETS \\
& VIIV & 1 & - nascent & SETS \\
\hline $\begin{array}{c}\text { Cubital tunnel } \\
\text { Acute/chronic } \\
\text { Injury }\end{array}$ & II/III & 1 & $1 /-$ & SETS \\
\hline
\end{tabular}

Figure 3: Indications for supercharged end to side nerve transfer [16].

These indications have to be able to make a sketch of a therapeutic algorithm for cubital tunnel syndrome, where the supercharge technique finally has a place [21] (Figure 4). 


\section{Journal of Orthopedics \& Bone Disorders}

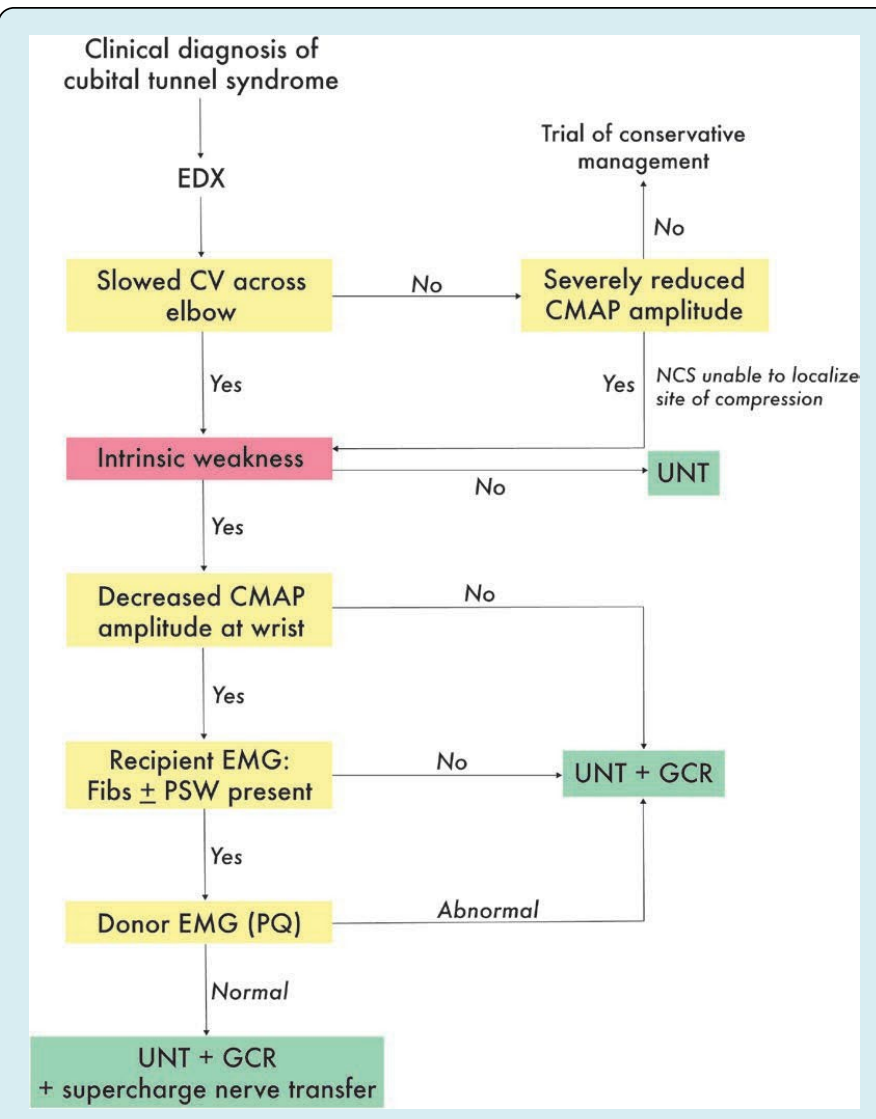

Figure 4: Algorithm of the treatment in ulnar disease [21].

\section{SETS Complications and Contraindications}

Donor muscle deficiency: Contrary to what was thought the first time the technique was used, it has been shown that the procedure does not cause a significant deficit in donor nerve muscle function after the operation, because there is still a complete pronation force with a pronator intact, the pronator round. One study was devoted to confirming this by examining a case (level of evidence IV) [15].

Davidge, et al. [12] corroborated this when reviewing all their patients undergoing the technique, with a mean followup of $8.0 \pm 5.7$ months, and no patient demonstrated weak pronation after the operation [12]. The latter provides more relevance when performed on a larger sample (55 patients).

Complications of the surgical technique: Therefore, ruling out pronation deficit as a controversy, we looked for possible complications in all the studies reviewed. In some of them he did not focus on them, and only mentioned the additional operating time, the possible temporary degradation of sensory or motor function and the risk of postoperative bleeding or wound infection (level IV-V evidence studies).
Barbour, et al. They are the first to discuss procedural complications in their study, and they found none of these complications in their practice [15]. In the 2019 systematic review, no complications are reported in any of the patients in the articles included, reaffirming the practically null morbidity of the technique [1].

Of all the studies, the only complication that is demonstrable and that some reviewed studies have reflected is the additional time involved in adding the technique in surgical practice, adding a time of 20-40 minutes [14,21].

\section{Factors Influencing}

But the articles found not only reflect the complications of the technique, but some of them (level of evidence IV) speak of the factors that influence its course. Most of these studies are expert opinions on their supercharge experience. It is important to remember that function can improve up to 5 years after repair, not immediately. This is due to continuous regeneration and nerve innervation, but also due to psychological adaptation to new innervation patterns [18].

Also the age at the time of repair has consistently shown to be able to significantly affect the result. One of the studies (level of evidence IV) stated on average that children recovered $87 \%$ of normal function compared to $67 \%$ in adolescents [18].

A major obstacle is also performing coaptation under stress. To maximize the result, coaptation should be performed as proximal as necessary on the ulnar nerve to eliminate tension. Already in 2012 Barbour et al. (level of evidence IV) recommended that the measurement should be 8 to $9 \mathrm{~cm}$ proximal to the wrist crease [15].

In conclusion, it is true that injuries to the forearm can create a heterogeneous pattern of motor and sensory deficiencies in the hand, which requires a detailed examination before surgical treatment, which will help with better management and will prevent the prognosis from darkening [18].

Contraindications: An expert review on ulnar nerve injuries (level of evidence IV) found compiles the contraindications of the technique described in the literature [16].

- It is not recommended to perform it in those patients in which a different treatment method will result in a better or equivalent result with less morbidity (although SETS has shown practically no morbidity as I will cite in the following paragraphs).

- Injuries to the distal nerve near the site of motor and 


\section{Journal of Orthopedics \& Bone Disorders}

sensory innervation. These injuries must be repaired mainly or with a nerve graft.

- Those with Sunderland type I injury, these injuries should be treated with observation without surgical intervention, as recovery is to be expected.

- Patients who have already experienced irreversible muscle atrophy and fibrosis due to the time elapsed since their injury. Tendon transfers are more appropriate in these patients.

SETS in severe ulnar disease: The NIA to ulnar SETS nerve transfer was originally designed for severe mototic injuries of the ulnar nerve. As already mentioned, in compressive nerve pathology, it was first performed in 2009 in a patient with severe recurrent cubital tunnel syndrome and marked intrinsic atrophy. At that time, excellent results were seen in this clinical setting, which is shown in the study we have found of Barbour (level of evidence IV) and it is from there that it is proposed to be able to use this procedure routinely in the treatment of intrinsic atrophy of the ulnar nerve of a severe nature [15].

Subsequently, the veracity of this statement is tested in other studies of the same level of evidence, when reviewing patients undergoing the technique, concluding that SETS could be a useful technique to increase intrinsic muscle function in severe injuries in continuity of the ulnar nerve where options existed limited surgical $[11,12]$.

In the first retrospective cohort study (level of evidence IV) on supercharge, it was demonstrated that these patients with severe ulnar neuropathy (clinically evidenced and electro diagnostic intrinsic denervation) can recover their intrinsic function with EESS. In fact, more than $70 \%$ of patients achieved grade 3 or higher dorsal interosseous muscle strength relative to $15 \%$ at baseline. This was an important finding, as the results in this population are generally considered poor. However, the level of evidence remained poor [12].

SETS motor transfer had been shown to allow reinnervation, and to reverse clinically intrinsic muscle atrophy [17], however, the degree of intrinsic recovery was not attributable to transfer. Although this is something that could be measured in animal models, some studies affirm that supercharge not only preserves the endplates but also encourages axonal regeneration along the pathway $[17,19,22,23]$. However, this is much more difficult to prove in the clinical situation and is the focus of future research Therefore; no high-level evidence study has yet been published that specifically addresses the use of the technique in severe ulnar disease.

\section{Results on Indicated Treatment in Ulnar Entrapment}

A total of eight articles that discussed the indicated treatment in ice cube entrapment were analyzed. None included the SETS technique in their therapeutic arsenal, but the different types of treatment used in compression ulnar injury did.

In the literature, several surgical techniques have been reported for decompression of the ulnar nerve in the elbow, without any of them being established as the "gold standard" treatment. Options include: simple or in situ decompression and decompression with anterior nerve transposition, either submuscular, intramuscular, or subcutaneous [4].

One of the expert studies (level of evidence IV) collected all the information so far, being an updated review of the ulnar entrapment syndrome treatment criteria, focusing on the difference between the ulnar nerve releases procedures at the elbow level. : Simple local decompression and decomposition associated with previous transposition, without reaching any decisive conclusion [8].

The rest of the available literature regarding the difference between these two techniques has not been able to demonstrate a statistically significant difference between these procedures, as far as clinical results of some studies are concerned. This fact may be attributable to the use of multiple classification systems and outcome assessment scales to evaluate patients treated for cubital tunnel syndrome, making it difficult to interpret the data due to their heterogeneity [24].

Similarly, other articles found led by some experts indicate that simple decompression and decomposition with transposition are equally effective and safe in ulnar syndrome, even when nerve failure is severe level of evidence IV). This was demonstrated in particular with a study of 55 patients (retrospective level of evidence case study IV) who were separated into two groups according to the surgical technique: anterior subcutaneous transposition and simple decompression of the ulnar nerve. Both groups demonstrated an improvement in ulnar nerve function compared to the preoperative period, and ulnar nerve palsy was not observed in any of our patients. Although both were effective, the authors concluded that we would favor simple decompression, since it is a less extensive procedure, and that decomposition with transposition is associated with deeper and superficial wound infections than simple decompression alone. In addition, they affirm that the recurrent entrapment of the ulnar nerve and dislocation is a disadvantage of simple decompression, which is why how the ulnar syndrome 


\section{Journal of Orthopedics \& Bone Disorders}

usually recurs and does have to be transposed at present in this case $[6,25,26]$.

Regarding the type of specific transposition, a study with a high level of evidence (level II) concluded that both operating methods are an effective alternative to treat ulnar tunnel syndrome but that since the subcutaneous has less trauma, it would be a better option for some elderly patients [27].

In another recent study (and after this one just discussed) that also had a level II of evidence, it reported again the long-term results of a consecutive surgical series of previous subcutaneous transpositions (70 patients) and reviewed the literature relevant (a total of 34 articles evaluating the outcome of different surgical techniques). The previous subcutaneous transposition had the lowest recurrence rate with an excellent efficacy and safety profile. The favorable predictive role for the outcome of the preoperative neurological status was confirmed (McGowan). The good long-term clinical results of the present series and the results of the literature analysis confirm the value of anterior subcutaneous transposition of the ulnar nerve at the elbow. This technique is particularly effective in most severe compressions, where the results are comparable with cases of intermediate neuropathy [26].

Reviewing what has been done to date (recent level IV evidence study), highlights the decomposition plus anterior transposition and specifically the subcutaneous subtype [8]. The timing of surgery is also debated. In a level II study of evidence, the long-term results of a consecutive surgical series of anterior subcutaneous transpositions were reported and it was suggested that early surgical treatment in ulnar neuropathy at the elbow brings effectiveness and safety to the anterior subcutaneous transposition, even in more advanced diseases [26].

This is the reason that despite the extensive therapeutic arsenal that existed, not achieving full satisfaction with any of the treatments used so far in severe ulnar injury, is the main reason for this review. And it's also because just over ten years ago, SETS emerged as a specific nerve transfer technique with promising results that could solve this problem.

Although no guideline or review on the treatment of ulnar tunnel syndrome is collected yet, it is believed that SETS may be a valid add-on surgical treatment in many situations where results remain consistent. In addition, on some occasion when the chosen therapeutic option does not go well $(19 \%$ require revision surgery after primary operation on the elbow), in such cases, if fibrillations are present in the intrinsic EMG, and there is a significant decrease in the amplitude of the compound muscle action potential, can be considered a supercharging nerve transfer at the time of the secondary procedure [21].

In addition, the most up-to-date study results speak to endoscopic decompression in situ techniques developed in recent years. A series of cases from the Morales Meseguer Hospital [24], spoke of the endoscopic release of the ulnar nerve, in selected patients, presenting good short-term results, especially for the relief of sensory symptoms and in terms of patient satisfaction. Furthermore, the complication rate is very low, achieving an early recovery of the patients. However, this technique should be compared with the rest in long-term randomized studies.

However, in a subsequent systematic review (level of evidence 2), it was concluded that open and endoscopic decompression is equally effective in improving clinical function, but with the endoscopic approach, a significantly higher rate of postoperative hematoma occurred [6].

In this same Cochrane review, we summarize the main outcomes of ulnar injury treatments for participants who underwent surgical procedures, but there were no studies comparing surgical treatment with conservative treatment to support this in a trial setting checked [6].

\section{Discussion}

The SETS transfer from anterior interosseus to ulnar motor nerve has gained popularity in recent years, as we have seen with several series of those found, which report good clinical results $[2,12,21]$.

Within an ideal framework for surgical innovation (consisting of the phases: idea, development, exploration, evaluation, long-term follow-up), this technique is still in the exploration stage, in which its purpose is to share details for those early users who use supercharged nerve transfer in patients with severe cubital tunnel syndrome [21].

\section{Difficulty Defining Severity in Ulnar Syndrome}

One of the problems that have been found in the reviewed articles is the difficulty in defining what a serious condition in ulnar entrapment syndrome is. In most of them it is not defined, it is taken for granted or simply the only severity criterion on which it is based is the result of the EMG (significant intrinsic atrophy evidenced in the reduction of the amplitude of the muscle action potential) [16,21].

\section{The Difference between Compression and Section Injuries}

In most of the articles reviewed, a distinction is made 


\section{Journal of Orthopedics \& Bone Disorders}

between two injury mechanisms of the ulnar nerve: the nerve section versus nerve compression. The entire nervous section is mostly caused by severe trauma that causes severe inflammation, and the second, the compression section, is the focus of our work.

The level of ulnar nerve injury is also a topic of discussion, because depending on whether it is more proximal or distal, one treatment or another is recommended. And the problem is that some of the reviewed articles do not discriminate this, and SETS in particular is recommended for more proximal injuries axons have to cross longer distances to reach the terminal organs and during this time, multiple irreversible changes can occur that negatively affect the result [14].

\section{Conservative Treatment Versus Surgical}

Regarding therapy, the results reported in the case studies have yielded good results with conservative treatment in mild cases, but large comparative published studies are lacking [4].

Only two studies have been found on the treatment of ulnar neuropathy using conservative treatment as the comparator. The available comparative treatment evidence is not sufficient to support a multiple treatment meta-analysis to identify the best treatment for ulnar syndrome [26].

\section{Supercharge Studies, Study Proposal Due to Lack of Solid Evidence}

Although more data is needed to elucidate specific indications, this same technique may be applicable for severe cubital tunnel syndrome according to the indications collected by the reviewed articles [15]. The concept of an end-to-side transfer with overfeeding may be applicable to nerve injuries that previously could not be treated with surgery or even to other nerve injuries in addition to ulnar nerve injuries. If the technique continues to be compatible, there will surely be additional SETS transfers that will be devised and employed.

In addition, some articles add that the severity of axonal loss may not correlate with the amount of intrinsic weakness in the examination, because function is preserved until there is a loss of $70-80 \%$ of the set of motor units, therefore with this The importance of performing the EMG as a preoperative test is emphasized, although as we have stressed before, it must be accompanied by other tests (Twenty-one). Therefore, a large prospective multicenter study with standardized preoperative and postoperative assessments would be necessary; to include electrodiagnostic studies and a more detailed analysis of complications, to effectively understand the efficacy of EESS.
Future solid research is still needed to determine the efficacy of the SETS NIA transfer to elucidate the source of axonal regeneration resulting in functional muscle recovery in these patients before it can become widespread practice among surgeons [20].

We want to propose how we would develop the prospective cohort study that would endorse this technique in severe ulnar injury. The design that we propose is reflected in attached document II.

\section{Complications not Mentioned in the Studies}

The general contraindication mentioned multiple times in the reviewed articles from SETS of NIA to ulnar nerve in compression pathology of that nerve, is when the integrity of the donor nerve (NIA) is not assured. None of the studies, it was stated that, although there are other muscles that are innervated by the anterior interosseum, and even if they are intact, if the pronator square is not, the SETS technique cannot be performed with the same reliability. Therefore, the EMG of this peroperative muscle is essential [29].

Therefore, on these occasions where the NIA is not available, the solution in patients with ulnar lesions is that the branches of the posterior interosseous nerve (PIN) can be transferred through the interosseous membrane to the ulnar nerve, although the results of these transfers have not been as satisfactory as those using ISAs $[30,31]$.

Suboptimal clinical results are related to variations in patient selection and differences in surgical technique. As the last article about SETS and its indications tells us: the proper selection of patients, meticulous surgical technique and reported postoperative rehabilitation are key elements to obtain favorable results with this nerve transfer in patients with cubital tunnel syndrome, even more so if they are severe.

\section{Conclusion}

The conclusions obtained have been:

- There is no prospective level I studies supporting the use of EESS in compressive ulnar neuropathy. .

- There are retrospective studies confirming the indication of EESS of anterior interosseus in the treatment of severe compressive ulnar neuropathy.

- In updated studies, it has been possible to elucidate an algorithm sketch that could be useful in the therapeutic management of patients with compression ulnar symptoms, to know when it is convenient to use the technique in question.

- Defining ulnar entrapment as serious requires clinical requirements, physical examination and complementary 
tests such as conduction studies and electromyograms

- Electromyographic tests should include: a normal donor nerve electromyogram (to be performed in a pronator square), a preoperative electromyogram of the injured nerve that must have a reduced amplitude of compound muscle action potential (demonstrating axonal loss) and an electromyogram to determine if the denervated motor end plates remain receptive to reinnervation (check they have spontaneous activity and this is shown by fibrillation potentials and / or acute positive waves).

- The technique has not shown any side effects or complications, except the increase in surgery in 40 minutes. Although they have not been included in the articles, we must not neglect other possible complications such as: those derived from prolonged ischemia, the extensive surgical approach, bleeding and infections, as well as higher learning curves in the implementation of supercharge by surgeons.

- In general, with whatever surgical treatment method is used, the functional results of cubital tunnel syndrome surgeries are generally good if the nerve is not very involved.

\section{References}

1. Dunn JC, Gonzalez GA, Fernandez I, Orr JD, Polfer EM, et al. (2019) Supercharge End-to-Side Nerve Transfer: Systematic Review. Hand.

2. Baltzer H, Woo A, Oh C, Moran SL (2016) Comparison of Ulnar Intrinsic Function following Supercharge Endto-Side Anterior Interosseous-to-Ulnar Motor Nerve Transfer: A Matched Cohort Study of Proximal Ulnar Nerve Injury Patients. Plast Reconstr Surg 138(6): 12641272.

3. MCCABE SJ (2009) What Is the Best Surgical Procedure for Cubital Tunnel Syndrome? Evidence-Based Orthopaedics, Saunders, Elsevier, pp: 75-79.

4. Samir S, Joe MD (2019) Hand Nerve Compression Syndromes, StatPearls.

5. Kong L, Bai J, Yu K, Zhang B, Zhang J, et al. (2018) Predictors of surgical outcomes after in situ ulnar nerve decompression for cubital tunnel syndrome. Ther Clin Risk Manag 14: 69-74.

6. Pietro C, Giuseppe LT, Roberto P, Fabio G, Luca P (2016) Treatment for ulnar neuropathy at the elbow. Review 11(11): CD006839.

7. Latinovic R, Gulliford MD HR (2006) Incidence of common compressive neuropathies in primary care. J Neurol Neurosurg Psychiatry 77(2): 263-265.
8. Miguel AMF (2011) Sindromes de atrapamiento nervioso (SAN). Rev espanola Investig quirurgicas. 14(3): 168180.

9. Strohl AB, Zelouf DS (2017) Ulnar Tunnel Syndrome, Radial Tunnel Syndrome, Anterior Interosseous Nerve Syndrome, and Pronator Syndrome. J Am Acad Orthop Surg 25(1): e1-e10.

10. Salva GC, Perez CU (2006) Terrades Cladera Compressive neuropathy of the ulnar nerve at the elbow: diagnosis and treatment. Med Balear 21(3): 32-36.

11. Wilson TJ (2019) Novel Uses of Nerve Transfers. Neurotherapeutics 16(1): 26-35.

12. Davidge KM, Yee A, Moore AM, Mackinnon SE (2015) The supercharge end-to-side anterior interosseous-to-ulnar motor nerve transfer for restoring intrinsic function: Clinical experience. Plast Reconstr Surg 136(3): 344e-352e.

13. Jarvie G, Hupin Debeurme M, Glaris Z, Daneshvar P (2018) Supercharge End-to-Side Anterior Interosseous Nerve to Ulnar Motor Nerve Transfer for Severe Ulnar Neuropathy: Two Cases Suggesting Recovery Secondary to Nerve Transfer. J Orthop case reports 8(5):25-28.

14. Koriem E, El-Mahy MM, Atiyya AN, Diab RA (2020) Comparison Between Supercharged Ulnar Nerve Repair by Anterior Interosseous Nerve Transfer and Isolated Ulnar Nerve Repair in Proximal Ulnar Nerve Injuries. J Hand Surg Am 45(2):104-110.

15. Barbour J, Yee A, Kahn LC, MacKinnon SE (2012) Supercharged end-to-side anterior interosseous to ulnar motor nerve transfer for intrinsic musculature reinnervation. J Hand Surg Am 37(10): 2150-2159.

16. Patterson JMM (2016) High Ulnar Nerve Injuries. Nerve Transfers to Restore Function. Hand Clin 32(2): 219-226.

17. Isaacs J (2013) Supercharged End-to-Side Nerve Transfer: Too Soon for "prime Time"? J Hand Surg Am 38(3): 617-618.

18. Woo A, Bakri K, Moran SL (2015) Management of ulnar nerve injuries. J Hand SurgAm 40(1): 173-181.

19. Nadi M, Ramachandran S, Islam A, Forden J, Guo GF, et al. (2019) Testing the effectiveness and the contribution of experimental supercharge (reversed) end-to- side nerve transfer. J Neurosurg 130(3): 702-711.

20. George S, Power DM (2020) Letter to the Editor Regarding "Supercharge End-to-Side Nerve Transfer: A Systematic Review." Hand 15(3): 428-429. 
Journal of Orthopedics \& Bone Disorders

21. Power HA, Kahn LC, Patterson MM, Yee A, Moore AM, et al. (2020) Refining Indications for the Supercharge End-to-Side Anterior Interosseous to Ulnar Motor Nerve Transfer in Cubital Tunnel Syndrome. Plast Reconstr Surg 145(1): 106e-116e.

22. Farber SJ, Glaus SW, Moore AM, Hunter DA, Mackinnon SE, et al. (2013) Supercharge nerve transfer to enhance motor recovery: A laboratory study. J Hand Surg Am 38(3): 466-477.

23. Poppler LH, Schellhardt LM, Hunter DA, Yan Y, MacKinnon SE, et al. (2017) Selective Nerve Root Transection in the Rat Produces Permanent, Partial Nerve Injury Models with Variable Levels of Functional Deficit. Plast Reconstr Surg 139(1): 94-103.

24. Gomez JEG, Guillen JFA, Minon-Ferran MR, Grau JA, Julia FJC, et al. (2013) Liberacion endoscopica del tunel cubital. Tecnica quirurgica y resultados preliminares. Arch Med del Deport 30(158): 354-358.

25. Taskin A, Kamil Y, Şemmi K, Cemil K, Serkan S (2018) Comparison of Simple Decompression and Anterior Subcutaneous Transposition of the Ulnar Nerve for the Treatment of Cubital Tunnel Syndrome. Ortop Traumatol Rehabil 20(6): 475-481.

26. Lauretti L, DAlessandris QG, De Simone C, Remore LM,
Izzo A, et al. (2017) Ulnar nerve entrapment at the elbow. A surgical series and a systematic review of the literature. J Clin Neurosci 46: 99-108.

27. Liu CH, Chen CX, Xu J, Wang HL, Ke X Bin, et al. (2015) Anterior Subcutaneous versus submuscular transposition of the ulnar nerve for cubital tunnel syndrome: A systematic review and meta-analysis. PLoS One 10(6): 1-14.

28. Tong J, Dong Z, Xu B, Zhang C, Gu Y (2018) Predictors of surgical outcomes for severe cubital tunnel syndrome: a review of 146 patients. Acta Neurochir 160(3): 645-650.

29. Dy CJ, Brogan DM, Colorado BS (2019) Absence of the Pronator Quadratus Muscle Precluding Distal Nerve Transfer. J Hand Surg Am 44(6): 523.e1- 523.e5.

30. Phillips BZ, Franco MJ, Yee A, Tung TH, Mackinnon SE, et al. (2014) Direct radial to ulnar nerve transfer to restore intrinsic muscle function in combined proximal median and ulnar nerve injury: case report and surgical technique. J Hand Surg Am 39(7): 1358-1362.

31. Tung TH, Barbour JR, Gontre G, Daliwal G, Mackinnon SE (2013) Transfer of the Extensor Digiti Minimi and Extensor Carpi Ulnaris Branches of the Posterior Interosseous Nerve to Restore Intrinsic Hand Function : Case Report and Anatomic Study. J Hand Surg Am 38(1): 98-103. 